\title{
Can Nutrition Help in the Treatment of Infertility?
}

\author{
Antoine Aoun, Veronique El Khoury, and Roubina Malakieh \\ Faculty of Nursing and Health Sciences, Notre Dame University-Louaize, Zouk Mosbeh 72, Lebanon
}

\begin{abstract}
Infertility is defined as the inability to conceive after 12 months of unprotected intercourse or six months for women aged 35 years or older. The physical, emotional, psychological, and financial statuses of infertile couples are tremendously affected especially after undergoing diagnostic and/or curative treatments. Human fertility is influenced by multiple factors including female or male, and modifiable or non-modifiable factors. There is growing evidence that nutrition may play an important role in adjusting fertility-related outcomes in both men and women. The objective of our study was to summarize the latest data on nutritional factors (specific food groups, nutrients, and nutritional supplements) that have an impact on female or male sexual and reproductive function. PubMed and Google Scholar platforms were used to collect appropriate articles for the review using several combinations of keywords (infertility, diet, dietary supplements, antioxidants, and beverages). Adherence to a healthy dietary pattern favoring fish, poultry, whole grains, fruits, vegetables, and healthy fats, was related to better fertility in both genders. Despite the multifactorial etiology of sexual infertility, nutrition may affect the sexual/reproductive function in both women and men.
\end{abstract}

Keywords: antioxidants, beverages, diet, dietary supplements, infertility

\section{INTRODUCTION}

Infertility is defined as "the inability to conceive after 12 months of unprotected intercourse or six months for women aged 35 years or older" (American Society for Reproductive Medicine, 2014). According to a study published by the World Health Organization (WHO) which compiled data from 277 national surveys in 190 countries, worldwide rates of infertility between 1990 and 2010 have remained relatively constant (Mascarenhas et al., 2012; WHO, 2019). Thus, the WHO estimated that in 2010, 48.5 million couples worldwide were unable to conceive. The physical, emotional, psychological, and financial statuses of infertile couples are tremendously affected especially after undergoing diagnostic-curative treatments [e.g., in vitro fertilization (IVF)]. Human fertility is influenced by multiple factors including female factors (e.g., ovulation and uterine disorders), male factors (e.g., abnormal sperm production and function), medical factors (e.g., pelvic inflammatory disease and cancer), non-modifiable factors (e.g., genetics, gender, and age), and most importantly modifiable lifestyle factors (e.g., physical activity, overweight, nutrition, alcohol, smoking, stress, and long-term use of contraceptives) (Sharma et al., 2013; Acharya and Gowda, 2017).

Following a nutritious/well-balanced diet and being physically active are two bases of a healthy lifestyle whereby they can help maintain a healthy weight and reduce the risk of chronic diseases (WHO, 2020). It is wellknown that nutrition can play an important role in altering fertility-related outcomes in both men and women. In a large prospective cohort of 17,544 women in Nurses' Health Study (NHS)-II, after controlling for certain confounders [age, body mass index (BMI), alcohol intake, coffee intake, smoking, and oral contraceptive use], women with the highest intake of a fertility diet [comprised of full-fat dairy foods, iron (Fe), monounsaturated fats, and plant protein] during the preconception period, were found to have a $66 \%$ lower risk of infertility related to ovulatory disorders and a $27 \%$ lower risk of infertility due to other causes compared to women with the lowest intake of this type of diet (Chavarro et al., 2007). While there is growing evidence that nutrition may be associated with reproductive outcomes in both sex, there is still no official guidelines for reproductive-aged couples (Rossi et al., 2016). This review aims to summarize the latest data on dietary factors (e.g., specific food groups, nutrients, and nutritional supplements) that have a major 
impact on both female and male sexual and reproductive functions.

\section{MATERIALS AND METHODS}

Our study was undertaken in the PubMed and the Google Scholar databases in November 2020, using the descriptor medical subject headings, without limitation as to the publication period (with emphasis on the most recent papers). Studies involving animals were not included. The following keyword combinations were used: "infertility" and "diet" (43 articles), "infertility" and "dietary supplements" (42 articles), "infertility" and "antioxidants" (6 articles), and "infertility" and "beverages" (15 articles). Eight articles were in common between the different combinations. Out of the total 104 articles, 24 were literature reviews, 68 were original studies, and 12 were reports from web pages of agencies and organizations. The above steps are shown in Fig. 1.

\section{RESULTS AND DISCUSSION}

Our review findings were reported in terms of pregnancy outcomes and semen variables where most of the studies reported improvement in no less than one of these outcome measures in the experimental group. Some studies that investigated the effect of dietary intake reported a positive correlation between specific macronutrient(s) or micronutrient(s) and the risk of infertility, while others reported conflicting results. The impact of various nutritional factors on male and female fertility are summarized in Table 1 and Table 2 , respectively.

\section{Dietary patterns}

Males: Healthy dietary patterns [e.g., Mediterranean and Prudent diets (MedDiet and PD, respectively)] have been associated with better sperm quality parameters in a wide range of studies in North America, Europe, the Middle East, and East Asia (Amaral et al., 2014). However, the
Western diet (WestDiet) characterized by a high intake of red and processed meat, refined grains, snacks, highenergy drinks, and sweets was unrelated to conventional semen quality parameters (Gaskins et al., 2012). The MedDiet is characterized by high intake of olive oil, nuts, legumes, fruits, vegetables, and whole cereals, moderate intake of fish, poultry, and wine, and low intake of dairy products, red or processed meats, and sweets. The PD is also characterized by a high intake of fruits, vegetables, chicken, fish, legumes, and whole grains (Gaskins et al., 2012). A study by Jurewicz et al. (2018) showed that PD has a positive association with increased sperm concentration, higher levels of testosterone (TT) and decreased deoxyribonucleic acid (DNA) fragmentation index. In a more recent case-control study involving 225 partners of couples attending an infertility clinic, consumption of MedDiet (defined by high intakes of fruits, vegetables, fish, and whole grains) was significantly associated with higher sperm concentration, total sperm count, and sperm motility (Karayiannis et al., 2017). These findings were similar to Ricci et al. (2018) and Cutillas-Tolín et al. (2015) findings; however, there was no association with semen volume. Furthermore, MedDiet (defined by high intakes of seafood, poultry, whole grains, legumes, skimmed milk, fruits, and vegetables) was associated with lower sperm DNA fragmentation (SDF) (Nassan et al., 2018). However, these positive associations were mainly present in men with poor semen quality and total motile sperm counts of $<10$ million (Oostingh et al., 2017). However, Danielewicz et al. (2018) and Eslamian et al. (2017) showed that the WestDiet (defined by frequent consumption of sweets and snacks, processed meat, animal fat, refined grain products, red meat, potatoes, and dairy products) was positively associated with abnormal semen parameters (abnormal count, progressive motility, and morphology of sperm). Although the definition of a healthy dietary pattern slightly varies across studies, it was consistently associated with better semen quality.

Females: Several studies evaluated the influence of the MedDiet on female fertility especially in women undergoing IVF. A nested case-control study of university gradu-

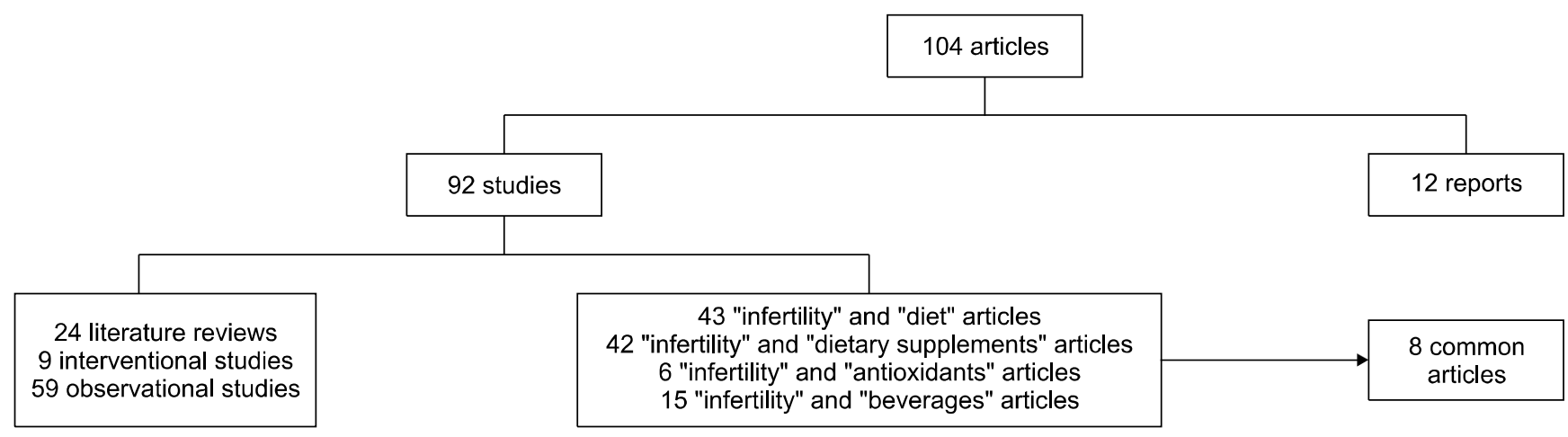

Fig. 1. Stages of study selection and inclusion of articles. 
Table 1. Summary of literature on the association between diet and male fertility

\begin{tabular}{|c|c|c|}
\hline Nutritional factors & Findings & References \\
\hline Dietary patterns & $\begin{array}{l}\text { Healthy eating patterns positively affect semen quality } \\
\text { and improve fecundity, while unhealthy diets had the } \\
\text { opposite relationship. }\end{array}$ & $\begin{array}{l}\text { Cutillas-Tolín et al. (2015); Eslamian et al. (2017); } \\
\text { Karayiannis et al. (2017); Danielewicz et al. (2018) }\end{array}$ \\
\hline Proteins & $\begin{array}{l}\text { High intake of dairy products might affect semen } \\
\text { quality and fertility. Limited evidence is available } \\
\text { from human studies on the effect of soy on fertility; } \\
\text { however, most of them showed no harmful effect. }\end{array}$ & $\begin{array}{l}\text { Jacobsen et al. (2014); Mínguez-Alarcón et al. } \\
\text { (2015); Vanegas et al. (2015); Gaskins et al. } \\
\text { (2018); Nassan et al. (2018); Wise et al. (2018) }\end{array}$ \\
\hline Dietary fats & $\begin{array}{l}\text { TFAs are related to reduced fertility, whereas } \omega \text {-3FAs } \\
\text { are protective against SDF, } T \text {, and testicular volume. }\end{array}$ & $\begin{array}{l}\text { Mínguez-Alarcón et al. (2017); Salas-Huetos et al. } \\
\text { (2018) }\end{array}$ \\
\hline Carbohydrates & $\begin{array}{l}\text { Diets with low-glycemic load that contain high } \\
\text { amounts of whole grains might have positive impact } \\
\text { on fertility. }\end{array}$ & Liu et al. (2015) \\
\hline Antioxidants & $\begin{array}{l}\text { Antioxidant supplementation improves semen quality } \\
\text { and may increase the probability of clinical pregnancy } \\
\text { and live birth. }\end{array}$ & $\begin{array}{l}\text { Ahmadi et al. (2016); Majzoub and Agarwal (2018); } \\
\text { Alahmar (2019); Li et al. (2019); Henkel et al. } \\
\text { (2019) }\end{array}$ \\
\hline Vit B12 supplement & $\begin{array}{l}\text { Vit B12 may be protective against fertility by increasing } \\
\text { sperm count, motility and minimizing sperm DNA } \\
\text { damage. }\end{array}$ & Banihani (2017) \\
\hline Vit D supplement & $\begin{array}{l}\text { Vit } D \text { may positively affect semen quality and sperm } \\
\text { motility but not sperm concentration. }\end{array}$ & $\begin{array}{l}\text { Zhu et al. (2016); Abbasihormozi et al. (2017); de } \\
\text { Angelis et al. (2017); Bosdou et al. (2019) }\end{array}$ \\
\hline Zn supplements & Zn may elevate sperm quality in infertile males. & $\begin{array}{l}\text { Colagar et al. (2009); Zheng et al. (2012); Shi et al. } \\
\text { (2014); Zhao et al. (2016); Lee (2018) }\end{array}$ \\
\hline $\begin{array}{l}\text { Fa and } \mathrm{Zn} \\
\text { supplement }\end{array}$ & $\begin{array}{l}\text { Fa and Zn may impose a greater influence only on } \\
\text { sperm concentration, morphology, and serum folate } \\
\text { level. }\end{array}$ & $\begin{array}{l}\text { da Silva et al. (2013); Irani et al. (2017); } \\
\text { Schisterman et al. (2020) }\end{array}$ \\
\hline Iron & $\begin{array}{l}\text { Iron may be inversely related to sperm concentration } \\
\text { and motility. }\end{array}$ & Adoamnei et al. (2019) \\
\hline CoQ10 supplement & $\begin{array}{l}\text { No significant correlation between CoQ10 and TT } \\
\text { levels. }\end{array}$ & Banihani (2018) \\
\hline DHA supplement & $\begin{array}{l}\text { DHA may increase } \omega-3 F A s \text { and DHA concentration } \\
\text { in seminal plasma, TAC, and decrease SDF. }\end{array}$ & Martínez-Soto et al. (2016) \\
\hline Beverages & $\begin{array}{l}\text { Occasional/moderate intake of alcohol and caffeine } \\
\text { does not affect semen quality, while high intake of } \\
\text { these beverages or SSBs negatively affects semen } \\
\text { quality. }\end{array}$ & $\begin{array}{l}\text { Liu et al. (2015); Wesselink et al. (2016); Karmon } \\
\text { et al. (2017); Ricci et al. (2017); Ricci et al. (2018); } \\
\text { Ghosh et al. (2019) }\end{array}$ \\
\hline
\end{tabular}

TFA, trans fatty acid; $\omega$-3FA, omega-3 fatty acid; SDF, sperm DNA fragmentation; TT, testosterone; DHA, docosahexaenoic acid; Vit B12, vitamin B12; Vit D, vitamin D; CoQ10, coenzyme Q10; TAC, total antioxidant capacity; Zn, zinc; Fa, folic acid; SSB, sugarsweetened beverage.

ates in Spain showed that women with high adherence to the MedDiet had lower odds [0.56, 95\% confidence interval (CI): 0.35 0.95] of having fertility problems (Toledo et al., 2011). A recent prospective cohort study involving 244 women showed that there was no association between MedDiet and IVF outcomes or the frequency of implantation. However, the MedDiet score was positively associated with pregnancy and live birth particularly in women $<35$ years old (Karayiannis et al., 2017). Similarly, Gaskins et al. (2019) showed that higher adherence to MedDiet was associated with an increased probability of live birth among women undergoing assisted reproductive technologies (ART). Another recent study showed a positive association between MedDiet and female fertility (Garruti et al., 2019).

\section{Protein}

Animal proteins (dairy, meat, and seafood): In a prospective cohort study, Souter et al. (2017) showed that higher dai- ry protein intake was associated with lower ovarian antral follicle counts (AFC) among women presenting for infertility treatment. Similarly, high intake of dairy products in healthy young men has been related to lower concentrations of TT, follicle-stimulating hormone (FSH), and luteinizing hormone (LH) which affect fertility (Nassan et al., 2018). In the NHS-II study, a prospective cohort of United States nurses, there was no relation between total dairy intake and risk of ovulatory infertility; however, anovulatory infertility was inversely associated with highfat and positively associated with low-fat dairy intake (Chavarro et al., 2007). In a more recent study "biocycle study", anovulation was more common among women with higher intake of yogurt and cream (Kim et al., 2017). Two preconception cohort studies by Wise et al. (2018) showed that in Denmark, where most milk is low-fat, total dairy consumption was associated with increased fecundability, whereas in the Pregnancy Study Online cohort, there was little association between dairy intake and 
Table 2. Summary of literature on the association between diet and female fertility

\begin{tabular}{|c|c|c|}
\hline Nutritional factors & Findings & References \\
\hline Dietary patterns & $\begin{array}{l}\text { Healthy dietary patterns (MedDiet and PD) have } \\
\text { been shown to improve the chance of pregnancy } \\
\text { and ART outcomes. Unhealthy diets (WestDiet) had } \\
\text { the opposite relationship. }\end{array}$ & $\begin{array}{l}\text { Toledo et al. (2011); Karayiannis et al. (2018); } \\
\text { Garruti et al. (2019); Gaskins et al. (2019) }\end{array}$ \\
\hline Proteins & $\begin{array}{l}\text { High-fat dairy products may increase risk of } \\
\text { infertility whereas non-dairy protein (fish and } \\
\text { white meat) have an important influence on fe- } \\
\text { male fertility. }\end{array}$ & $\begin{array}{l}\text { Braga et al. (2015); Kim et al. (2017); Souter et } \\
\text { al. (2017); Wise et al. (2018) }\end{array}$ \\
\hline Dietary fats & $\begin{array}{l}\text { TFAs may increase risk of metabolic disorders that } \\
\text { negatively affect ovarian functions; however, } \\
\omega-3 \text { FAs improve fecundability. }\end{array}$ & $\begin{array}{l}\text { Fontana and Della Torre (2016); Gaskins et al. } \\
\text { (2018); Wise et al. (2018) }\end{array}$ \\
\hline Carbohydrates & $\begin{array}{l}\text { Current evidence, though limited, suggest that diets } \\
\text { with low-GL that contain high amounts of whole } \\
\text { grains may benefit fecundity. }\end{array}$ & $\begin{array}{l}\text { Liese et al. (2003); Blomhoff (2005); Gaskins et al. } \\
\text { (2016); Chiu et al. (2018) }\end{array}$ \\
\hline Antioxidants & $\begin{array}{l}\text { Antioxidants might provide benefit for subfertile } \\
\text { women. }\end{array}$ & Showell et al. (2020) \\
\hline Vit D supplement & $\begin{array}{l}\text { Vit D may be beneficial only for women with } \\
\text { disorders like PCOS, insulin resistance, or } \\
\text { low anti-Mullerian hormone levels. }\end{array}$ & $\begin{array}{l}\text { Jukic et al. (2015); Somigliana et al. (2016); } \\
\text { Muscogiuri et al. (2017); Arslan and Akdevelioğlu } \\
\text { (2018); Mumford et al. (2018) }\end{array}$ \\
\hline Fa and $\mathrm{Zn}$ supplement & $\begin{array}{l}\text { Fa and Zn may decrease the risk of ovulatory } \\
\text { infertility, sporadic anovulation, and TTP. }\end{array}$ & Cueto et al. (2016); Chiu et al. (2018) \\
\hline Zn and Se supplement & $\mathrm{Zn}$ and Se may reduce TTP and risk of subfertility. & Grieger et al. (2019); Maeda et al. (2019) \\
\hline $\mathrm{Cu}$ & $\begin{array}{l}\text { Cu does not have an important influence on female } \\
\text { infertility. }\end{array}$ & Bawa and Tyagi (2017) \\
\hline $\mathrm{Hg}$ & $\begin{array}{l}\text { Intake of fish with high levels of } \mathrm{Hg} \text { may be of } \\
\text { concern to women planning pregnancy or preg- } \\
\text { nant women. }\end{array}$ & Maeda et al. (2019); Zhu et al. (2020) \\
\hline $\mathrm{Fe}$ & $\begin{array}{l}\text { Heme-Fe was much more associated with } \\
\text { fecundability than non-heme Fe. }\end{array}$ & Hahn et al. (2019) \\
\hline LC supplement & $\begin{array}{l}\text { LC may improve PCOS, amenorrhea disorders, sex } \\
\text { hormone levels, oocyte health, as well as TAC and } \\
\text { lipid peroxidation. }\end{array}$ & $\begin{array}{l}\text { Genazzani et al. (2011); Samimi et al. (2016); } \\
\text { life'sDHA (2020) }\end{array}$ \\
\hline Beverages & $\begin{array}{l}\text { High intake of beverages (alcohol, caffeine, and } \\
\text { SSBs) increases the risk of infertility. }\end{array}$ & $\begin{array}{l}\text { Schliep et al. (2015); Mikkelsen et al. (2016); } \\
\text { Lyngs } \varnothing \text { et al. (2017); Machtinger et al. (2017); } \\
\text { Arvizu Boy et al. (2018); Hatch et al. (2018) }\end{array}$ \\
\hline
\end{tabular}

MedDiet, Mediterranean diet; PD, Prudent diet; ART, assisted reproductive technology; WestDiet, Western diet; TFA, trans fatty acid; $\omega$-3FA, omega-3 fatty acid; GL, glycemic load; Vit D, vitamin D; PCOS, polycystic ovary syndrome; Fa, folic acid; Zn, zinc; TTP, time to pregnancy; Se, selenium; Cu, copper; Hg, mercury; LC, L-carnitine; TAC, total antioxidant capacity; SSB, sugar-sweetened beverage.

fecundability, but these associations were only among women younger than 30 years of age. Moreover, Shaaker et al. (2012) studied the effect of dietary fat [total, saturated fat (SF), monounsaturated fatty acids (MUFAs), polyunsaturated fatty acids (PUFAs), omega- 6 fatty acids $(\omega-6 \mathrm{FAs})$ omega-3 fatty acids ( $\omega-3 \mathrm{FAs})$, and trans fatty acids (TFAs)] on a range of preclinical and clinical outcomes in women undergoing IVF and found an inverse association between SF and the number of mature oocytes retrieved. Therefore, the association between dairy intake and fertility remains inconclusive, yet a positive association between high-fat dairy and infertility is present and this could be due to saturated fatty acids.

As for protein intake from non-dairy sources and its effect on fertility, Souter et al. (2017) showed that ovarian AFC was not affected by animal protein intake from nondairy sources among women attending a fertility clinic. On the other hand, a large prospective study by Braga et al. (2015) found that consumption of red meat and poul- try was inversely associated with the risk of infertility among women undergoing fertility treatment.

Regarding fish intake and the risk of infertility, Wise et al. (2018) and Gaskins et al. (2018) found that fish intake by both men and women was associated with shorter time to pregnancy (TTP). Another prospective cohort consisting of 351 women, showed that fish intake was positively associated with fertility; however, fish oil supplement use was not associated with live birth (Nassan et al., 2018). A common concern about recommending women who are pregnant or may become pregnant to consume fish is that seafood is the primary source of exposure to environmental contaminants [e.g., mercury (Hg)] (Nassan et al., 2018). This concern resulted in guidance from the Food and Drug Administration and the Environmental Protection Agency recommending pregnant women or those who may become pregnant to eat no more than 3 servings of seafood per week (US Food and Drug Administration, 2017). Most studies of 
fish intake and fertility showed that the benefits of fish consumption may outweigh the risk of environmental contaminants that might be carried by fish. However, certain factors such as the type or the amount of fish consumed might influence those benefits.

Plant protein (soy): Soy has received a large degree of attention as a potential reproductive toxicant since it is the main source of phytoestrogens for humans. Limited evidence is available from human studies; however, most showed no harmful effect (Jacobsen et al., 2014; MínguezAlarcón et al., 2015; Vanegas et al., 2015).

Only data from animal studies suggest that certain phytoestrogens may affect endocrine processes by influencing estrogen-dependent pathways and hypothesized that consumption of soy might affect fertility (Wocławek-Potocka et al., 2013; Amir et al., 2018). In a prospective study conducted among 184 men, soy intake was unrelated to the probability of live birth in couples undergoing infertility treatment (Mínguez-Alarcón et al., 2015).

Another prospective study done among 315 women, dietary soy intake was positively associated with the probability of having a live birth during infertility treatment with ART (Vanegas et al., 2015). Even though available data suggest no harmful effect, the present studies are not very recent and with small sample sizes (Jacobsen et al., 2014; Mínguez-Alarcón et al., 2015; Vanegas et al., 2015). Therefore, the association between soy protein intake and fertility remains inconclusive.

\section{Fats}

Fats, which comprise $30 \%$ to $40 \%$ of daily energy intake in Western countries, are important components of cell membranes. They modify the expression of enzymes involved in prostaglandin and steroid hormone metabolism both vital for reproduction (Wise et al., 2018).

Females: In two prospective cohort studies (North America and Denmark) of 1,290 women who were attempting to become pregnant, reduced fecundability among North Americans was associated with a high intake of TFAs and low intake $\omega$-3FAs (Wise et al., 2018). High intake of TFA was shown to increase the risk of metabolic disorders (e.g., insulin resistance, type 2 diabetes, and inflammatory markers) which negatively affect ovarian functions (Fontana and Della Torre, 2016).

In another prospective cohort study, seafood intake (canned tuna fish, fish, crab, shrimp, or other shellfish caught in an unknown location or in local water) was collected daily from 501 couples planning for pregnancy, and they were followed for 1 year or until pregnancy was detected. Couples with male and female partners who consumed eight or more seafood servings per cycle had $47 \%$ and $60 \%$ greater fecundity respectively than couples with male and female partners who consumed one or less seafood serving per cycle. However, the results might not be generalizable to all women of reproductive age since all couples were given fertility monitors to help time intercourse and ovulation. Moreover, there was no control for dietary confounders such as dietary supplements since the dietary assessment was not practical, and data on different types and sources of seafood was not collected during follow-up (Gaskins et al., 2018).

Males: In a Spanish cross-sectional study of 209 healthy males, $\omega$-3FAs were found to have a potential positive association with testicular function (testicular volume) whereas intake of $\omega-6$ FAs and TFAs appear to be negatively associated to it. Furthermore, intake of $\omega-6 \mathrm{FAs}$ was positively related to LH concentrations, and MUFAs were inversely associated with circulating free testosterone, TT, inhibin B concentrations, and testicular volume. Nevertheless, there is a possibility of reverse causation (nature of study) and errors due to having only one serum sample for each man (MInguez-Alarcón et al., 2017). In a FERTINUTS study, a 14-week randomized clinical trial (RCT), 119 healthy men, aged 18 35 years were allocated to 1 of 2 intervention groups: one group was fed the usual Western-style diet enriched with $60 \mathrm{~g}$ of a mixture of nuts/d (nut group), and the other was fed the usual Western-style diet without the nuts (control group). The inclusion of nuts in the Western-style diet reduced SDF and consequently notably improved vitality, motility, and morphology as well as the total sperm count. The study had several limitations: participants were men who followed a Western diet but in the context of a Mediterranean area, the sample size was small, $>10 \%$ of participants dropped out and the effect on semen parameters was only observed with $60 \mathrm{~g}$ nuts/d (smaller or larger amounts of nuts must be determined) (Salas-Huetos et al., 2018). Thus, higher intake of PUFAs, specifically $\omega-3 \mathrm{FAs}$, is probably beneficial for improving both female and male fertility due to their ability to regulate certain hormones (e.g., progesterone and TT) that are essential for successful implantations/pregnancies.

\section{Carbohydrates (CHO)}

Quantity and quality of dietary $\mathrm{CHO}$ influence glucose homeostasis and insulin sensitivity (Chiu et al., 2018), which may influence ovarian function. A common indicator of $\mathrm{CHO}$ quality is glycemic index (GI, a measure of the relative impact of carbohydrate-containing foods on blood glucose) whereas glycemic load (GL, product of the GI value of food and its $\mathrm{CHO}$ content) is an indicator of $\mathrm{CHO}$ quality, quantity, and amount of dietary fiber; related to the extent to which $\mathrm{CHO}$ has been refined (whole or refined grains).

Females: Total CHO consumption and GL are both associated with higher risks of ovulatory infertility (Chiu et al., 2018). A prospective study of 18,555 women showed that the quality of $\mathrm{CHO}$ in the diet had an impact on the 
risk of ovulatory infertility with a $78 \%$ greater risk for women with higher $\mathrm{CHO}$ consumption (Chavarro et al., 2009). A prospective study including 273 women attending a fertility clinic showed that higher preconception intake of whole grain was associated with a higher probability of live birth (Gaskins et al., 2016). This could be due to their antioxidant properties and impact on glycemia (Liese et al., 2003; Blomhoff, 2005).

Males: Liu et al. (2015) showed that high-CHO intake was associated with increased prevalence of abnormal total sperm motility and progressive motility. However, it is still unclear how much $\mathrm{CHO}$ (quantity) should this diet include or for how long the diet should be maintained for optimal outcomes; thus further studies are needed to investigate the optimum amount of carbohydrate and time of the intervention in relation to attempted pregnancy.

\section{Antioxidants}

Antioxidants [vitamin E, vitamin C, $\beta$-carotene, L-carnitine (LC), N-acetyl cysteine, co-enzyme Q10 (CoQ10), zinc ( $\mathrm{Zn})$, selenium (Se), folic acid (Fa), and lycopene] are substances that inhibit the oxidation of cells by scavenging existing free radicals. Free radicals are highly reactive molecules that contain one or more unpaired electrons and cause damage to the cells.

Males: Alahmar (2019) showed that decreased level of antioxidant causes an increase in oxidative stress which leads to sperm membrane lipid peroxidation, reduced motility, DNA damage of the sperm, poor pregnancy, and reduced ART outcomes. In a recent prospective cohort study of 171 men in couples undergoing infertility treatment, men's intake of $\beta$-carotene and vitamin $C$ was positively associated with fertilization rate but does not translate into higher pregnancy or live birth rates (Li et al., 2019). Similarly, Majzoub and Agarwal (2018) found that antioxidant supplementation has a positive impact on male fertility. Moreover, a study done by Ahmadi et al. (2016) showed that antioxidant supplementation (especially a combination of vitamin C, vitamin E, and CoQ10) effectively improves semen parameters in infertile men. However, Henkel et al. (2019) revealed that high intake of antioxidants may lead to reductive stress, which is reported to be as risky as oxidative stress to cells and can be the cause of several diseases including cancer and cardiomyopathy.

Females: Very few studies have been conducted to study the effect of antioxidant supplementation on female fertility. A study done by Showell et al. (2017) showed that taking an antioxidant may provide benefit for subfertile women. However, the evidence of these findings was limited by the risk of bias related to poor reporting of methods, imprecision, and inconsistency. The above results can be explained by the fact that antioxidants help reduce oxidative stress associated with reproductive cell oxida- tion and certain conditions such as endometriosis and polycystic ovary syndrome (PCOS).

\section{Vitamin B12}

Vitamin B12 or cobalamin is a water-soluble vitamin that acts as a co-factor in DNA synthesis and in both fatty acid and amino acid metabolism (Office of Dietary Supplements, 2020d). Over the past 20 years, study findings showed that vitamin B12 affects semen quality positively by increasing sperm count, motility, and minimizing sperm DNA damage (Banihani, 2017).

\section{Vitamin D}

Vitamin D is a fat-soluble vitamin that is naturally present in very few foods, added to others, and available as a dietary supplement. It is also produced endogenously when ultraviolet rays from sunlight strike the skin and trigger vitamin D synthesis. Vitamin D helps regulate calcium and phosphate in the body to keep bones, teeth, and muscles healthy (Office of Dietary Supplements, 2020e). Females: Endocrine Society Guidelines indicate sufficient 25-hydroxyvitamin D [25(OH)D] levels greater than 30 $\mathrm{ng} / \mathrm{mL}(75 \mathrm{nmol} / \mathrm{L})$, insufficient $25(\mathrm{OH}) \mathrm{D}$ levels ranging from 20.0 to $29.9 \mathrm{ng} / \mathrm{mL}(52 \sim 72 \mathrm{nmol} / \mathrm{L})$, and deficient 25(OH)D levels below $20 \mathrm{ng} / \mathrm{mL}$ (50 nmol/L) (Holick et al., 2011).

In a large cohort of premenopausal women aged 30 to 49 years $(n=1,430)$, vitamin $D$ was inversely related to urinary FSH and for every increase of $10 \mathrm{ng} / \mathrm{mL}$ of $25(\mathrm{OH}) \mathrm{D}$ serum levels, urinary FSH decreased by $14 \%$, consequently decreasing fertility rate (Jukic et al., 2015; Muscogiuri et al., 2017). Another case-control study compared early pregnancy levels of vitamin $\mathrm{D}$ between women who took $12 \sim 24$ months to get pregnant with agematched women conceiving in less than 1 year and found no association (Somigliana et al., 2016). Similarly, no association between baseline serum vitamin $\mathrm{D}$ levels or vitamin D deficiency $(<20 \mathrm{ng} / \mathrm{mL})$ and fecundability was found among a large cohort of women (Mumford et al., 2018).

In the case of vitamin $\mathrm{D}$ deficiency during infertility treatment, vitamin D supplementation can be recommended for women with disorders like polycystic ovary syndrome, insulin resistance, or low anti-Mullerian hormone levels; considering possible toxic effects of very high doses of vitamin D (Arslan and Akdevelioğlu, 2018).

Males: In a recent triple-blinded RCT of 330 men with infertility and vitamin D insufficiency who received either a single dose of 300,000 IU cholecalciferol (followed by $1,400 \mathrm{IU} / \mathrm{d}$, combined with calcium $500 \mathrm{mg} / \mathrm{d}$ for 150 days) or placebo, the number of spontaneous pregnancies was higher in the vitamin $\mathrm{D}$ group compared with the placebo group, yet there was no difference in sperm concentration (Bosdou et al., 2019). Moreover, vitamin D 
positively affects semen quality and vitamin $\mathrm{D}$ supplementation might enhance sperm motility in men with vitamin D deficiency, asthenozoospermia (reduced sperm motility), and sub-fertile men from couples enrolled in ART (Zhu et al., 2016; Abbasihormozi et al., 2017; de Angelis et al., 2017).

Most human studies suggest that vitamin D deficiency independently affects female and male fertility. However, there is still no strong and conclusive evidence from interventional studies; most studies were of small sample sizes with major heterogeneity with respect to the best vitamin $\mathrm{D}$ dose and duration.

\section{$\mathbf{Z n}$}

$\mathrm{Zn}$ is an essential mineral that is naturally present in foods, added to others, and available as a dietary supplement. It plays an important role in protein and DNA synthesis, immune function, and cell division (Office of Dietary Supplements, 2020f). Zn also acts as an antioxidant by scavenging superoxide anions, but it can turn into a prooxidant causing mitochondrial oxidative stress when supplemented in high amounts (Lee, 2018). Some studies showed that the $\mathrm{Zn}$ level in the seminal plasma of infertile males was extensively lower than that of normal males (Colagar et al., 2009; Zheng et al., 2012; Shi et al., 2014; Zhao et al., 2016). Also, Zn supplementation was shown to drastically elevate sperm quality of infertile males. This may be due to the importance of this mineral in the synthesis of DNA in sperm. However, these studies had small sample sizes and the association was not clear if the change in seminal plasma $\mathrm{Zn}$ concentration was caused by male infertility or vice versa.

\section{Fa and Zn}

$\mathrm{Fa}$ is the fully oxidized form of the folate water-soluble vitamin (B9) that is used in most dietary supplements. Fa acts as a co-enzyme in the synthesis of DNA and ribonucleic acid (RNA) and metabolism of amino acids (Office of Dietary Supplements, 2020b).

Males: In a 3-month double-blinded RCT that studied the effect of Fa supplementation by analyzing semen of 49 sub-fertile men (very small sample size) receiving $5 \mathrm{mg}$ of Fa daily and a control receiving placebo, no statistically significant improvement in motility, vitality, concentration, and morphology of the sperm was observed (da Silva et al., 2013). In addition, in a RCT of 2,370 couples planning infertility treatment, men were randomized by study center and planned infertility treatment to receive either $5 \mathrm{mg}$ of $\mathrm{Fa}$ and $30 \mathrm{mg}$ of elemental $\mathrm{Zn}$ or placebo daily for 6 months. The use of $\mathrm{Fa}$ and $\mathrm{Zn}$ supplementation by male partners in the treatment of infertility compared with placebo did not significantly enhance semen quality or couples' live births (Schisterman et al., 2020). In a meta-analysis of 6 RCTs, Fa supplementation alone in men affected sperm concentration but was not effective in improving sperm motility or morphology. Also, Fa and Zn supplementation did not affect serum TT, FSH, and sperm motility; nevertheless, it imposed a greater influence on sperm concentration, morphology, and serum folate level (Irani et al., 2017).

Females: Women from the NHS-II study, multivitamin users, specifically those using $\mathrm{Fa}$, had a lower risk of ovulatory infertility compared to nonusers (Chiu et al., 2018). Similarly, folate intake was inversely related to sporadic anovulation and TTP in a large Danish cohort (Cueto et al., 2016).

\section{$\mathrm{Zn}$, copper $(\mathrm{Cu})$, and Se}

$\mathrm{Cu}$ is an essential mineral naturally present in foods and dietary supplements. It is a cofactor for numerous enzymes involved mechanisms of the body such as energy production and Fe metabolism (Office of Dietary Supplements, 2020a).

Se is a trace element that is naturally present in foods and dietary supplements. Se is a constituent of selenoproteins with antioxidant properties important for reproduction and DNA synthesis (Office of Dietary Supplements, 2020c).

Females: A RCT of 74 females of reproductive age with infertility (small sample size) and a control group of fertile females with no gynecological disease showed that $\mathrm{Cu}$ but not $\mathrm{Zn}$ deficiency may have a considerable role in female infertility (Bawa and Tyagi, 2017). In a retrospective study of Australian women $(n=1,060)$ who participated in the Screening for Pregnancy Endpoints study, women with lower $\mathrm{Zn}$ or lower Se concentrations had a longer TTP and greater risk of subfertility (probably due to its potential importance in follicle growth and maturation), but no associations were found between $\mathrm{Cu}$ and subfertility or TTP (may be because of its potential importance in placentation rather than conception). However, this study had some limitations; females were prone to recall or misclassification bias, results were subject to confounding and it was hard to know if such measurements truly reflect the time these women were trying to conceive since the assessment of trace elements were measured at 14 to 16 weeks gestation, rather than pre-pregnancy (Grieger et al., 2019).

\section{$\mathrm{Hg}$ and $\mathrm{Se}$}

$\mathrm{Hg}$, a naturally found element and introduced contaminant, tends to affect the nervous system. The primary source of organic $\mathrm{Hg}$ in humans is the consumption of fish contaminated with methylmercury (Kimáková et al., 2018). Overall, larger- and longer-lived fish (e.g., king mackerel, marlin, orange roughy, shark, etc.) tend to have high levels of Hg.

A case-control study of 98 infertile women receiving 
fertility treatment and 43 fertile females provided blood samples and filled a questionnaire on lifestyle and dietary habits (Maeda et al., 2019). After adjusting for potential confounders (other metals), significant associations of infertility with increased $\mathrm{Hg}$ and decreased Se levels were established. However, the nature of this study helps establish an association but not causation between fish intake (exposure) and fertility (outcome); adding to that, it may be prone to selection and recall bias. Furthermore, a positive, insignificant, and non-linear association between $\mathrm{Hg}$ and infertility was found in a cross-sectional study of 1,796 participants from the National Health and Nutrition Examination Survey (2013 2016) (Zhu et al., 2020). Analyses identified an inflection point of 5.278 $\mu \mathrm{g} / \mathrm{L}$, when blood $\mathrm{Hg}>5.278 \mu \mathrm{g} / \mathrm{L}$, a 1 unit increase in $\mathrm{Hg}\left(\log _{2}\right)$ was associated with $157 \%$ greater adjusted odds of infertility. Even if few people showed a total blood $\mathrm{Hg}>5.278 \mu \mathrm{g} / \mathrm{L}$, yet, it is notable that even small increments of $\mathrm{Hg}$ exposure could drastically affect fertility rates. Therefore, women who are infertile should take into consideration the potentially toxic effect of $\mathrm{Hg}$.

\section{$\mathrm{Fe}$}

In a cross-sectional study of 209 healthy male university students in Spain, a statistically significant inverse correlation between Fe intake from foods and sperm concentration and motility was observed. However, further studies in male populations consulting for infertility problems are needed (Adoamnei et al., 2019). Hahn et al. (2019) found that heme Fe intake was associated with fecundability whereas non-heme Fe intake and supplement use were inconsistent (heme $\mathrm{Fe}$ is more readily absorbed by the body than non-heme Fe) but have some indication of beneficial effects on fertility among women having a higher possibility of Fe deficiency.

\section{CoQ10}

Males: CoQ10 is a component of the electron-transport chain responsible for generating adenosine triphosphate molecules from aerobic cellular respiration. So far, studies conducted on human males generally reveal an insignificant relationship between CoQ10 supplementation and TT levels (Banihani, 2018).

\section{LC}

Females: LC is a naturally occurring amino acid derivative often taken as a supplement for weight loss and helps regulate oxidative status of the female reproductive system (Agarwal et al., 2018). Several studies found that LC supplementation improves PCOS (Samimi et al., 2016) and amenorrhea disorders, as well as gonadotropins, sex hormone levels, and oocyte health (Genazzani et al., 2011). In a 12-week double-blinded RCT of 60 women, oral supplementation of $250 \mathrm{mg}$ LC improved total anti- oxidant capacity (TAC) and decreased lipid peroxidation (Jamilian et al., 2017). LC probably enhances female fertility by increasing energy production in oocytes and reducing free radicals to protect against oxidative damage to reproductive cells.

\section{Docosahexaenoic acid (DHA)}

Males: DHA, a long chain $\omega-3 \mathrm{FA}$, an important structural component of heart tissue, is the most abundant $\omega$-3FA in the brain and eye (life'sDHA, 2020). In a 10-week double blinded RCT, 32 males were assigned to the placebo group (received $1,500 \mathrm{mg} / \mathrm{d}$ of sunflower oil) and 42 males were assigned to the DHA group (received 1,500 $\mathrm{mg} / \mathrm{d}$ of DHA-enriched oil). Results showed that DHA supplementation increased $\omega-3$ FAs and DHA concentration in seminal plasma and TAC, and decreased SDF (Martínez-Soto et al., 2016).

\section{Alcohol}

Males: Ricci et al. (2017) showed that there is a detrimental effect of alcohol consumption on semen volume and morphology, mainly in daily, not occasional, consumers. Similarly, Condorelli et al. (2015) found that infertile patients in the group of daily drinkers had worse semen quality compared with other groups (occasional). A more recent study done by Ricci et al. (2018) found that moderate consumption of alcohol was positively associated with semen quality in male partners of infertile couples undergoing ARTs. Therefore, occasional alcohol intake does not seem to affect semen quality, whereas daily consumption has a negative effect on both semen volume and morphology.

Females: In the past few decades, a lot of publications have indicated an association between alcohol consumption and the fecundability among women; however, the results were largely controversial. Schliep et al. (2015) found that acute alcohol use increased TT, estradiol, and LH levels, with greater increases seen in women who binge drink. A prospective cohort study including 6,120 Danish female residents showed that the frequency of alcohol intake was not associated with fecundability (Mikkelsen et al., 2016). Hence, moderate alcohol consumption does not affect women's fertility, but higher amounts do.

\section{Caffeine and caffeinated beverages}

Coffee intake within moderation (3 to 4 cups a day) has a positive influence on a person's health (Poole et al., 2017). However, in higher doses, it may influence fertility by affecting sperm quality, ovulation, or menstrual characteristics (Wesselink et al., 2016).

Males: A prospective cohort study in North America including 2,135 pregnancy planners showed that caffeinated soda intake has an inverse dose-response relation with fecundability in males [ 1 and $\geq 2$ cans/d: fecundability 
ratios (FR) 0.77, 95\% CI: $0.56 \sim 1.05$ and FR 0.72, 95\% CI: $0.46 \sim 1.11$ for $0 \mathrm{can} / \mathrm{d}]$. Decaffeinated coffee and herbal/decaffeinated tea were associated with slightly decreased fecundability, whereas decaffeinated soda was not (Wesselink et al., 2016). Ricci et al. (2017) found that caffeine intake might negatively affect sperm DNA and therefore affect male fertility. In a study by Karmon et al. (2017) of 171 men, increased levels of TT were associated with increased caffeine intake, but with no adverse effect on semen quality. Moreover, this study only demonstrated that male caffeine intake was negatively correlated with live birth after ART. In summary, based on the current data, there is inconclusive evidence on the effect of caffeine on semen parameters and male fertility. Females: In a prospective cohort study of 340 women undergoing IVF, intake of caffeine was associated with poorer oocyte and embryo outcome; however, these associations did not affect or lead to poor clinical outcomes (Machtinger et al., 2017). Another prospective study including 7,574 Danish women, consumption of coffee, tea, or total caffeine were found to have no association with the risk of infertility (Soylu et al., 2018). Lyngsø et al. (2017) found no association between coffee/caffeine consumption and fertility among women/couples trying to conceive naturally or by receiving fertility treatment. Nevertheless, the European Food Safety Authority and WHO advise women planning to conceive or pregnant women to limit coffee consumption to a maximum of two to three cups/200 300 mg caffeine per day (EFSA NDA Panel, 2015; WHO, 2016).

\section{Sugar-sweetened beverages (SSBs)}

Females: In a case-control study including 11,317 women aged $<40$ years, consumption of SSBs was associated with a higher risk of infertility (Arvizu Boy et al., 2018). Similarly, Machtinger et al. (2017) and Hatch et al. (2018) found that women who drank sugar-sweetened sodas and energy drinks had lower fertilization rates compared with women who drank non-SSBs. This may be explained by the interference of sugar with reproductive hormones, egg maturation, and ovulation.

Males: Ghosh et al. (2019) showed that the intake of SSBs affects sperm parameters (except total sperm counts) negatively. Moreover, Liu et al. (2015) found that a greater intake of highly sweet snacks and SSBs is associated with lower sperm concentration.

In conclusion, the above compiled results show that despite the multifactorial etiology of reproductive dysfunction, dietary factors may affect reproduction in both males and females. To put it briefly, adherence to a healthy dietary pattern favoring healthy fats, fish, poultry, whole grains, fruits, and vegetables, is related to better fertility in both genders. Moreover, this review included some articles that only studied the effect of dietary patterns on couples undergoing ARTs, thus, future studies focusing on the effect of diet and couples not undergoing ARTs are needed. Because much of the above evidence came from observational studies of small sample sizes, future welldesigned and larger RCTs are essential to validate these findings to provide solid practical recommendations for couples planning a pregnancy. To increase the awareness of these couples, it is highly recommended that counseling on nutritional habits for both genders be implemented in preconception care worldwide.

\section{AUTHOR DISCLOSURE STATEMENT}

The authors declare no conflict of interest.

\section{REFERENCES}

Abbasihormozi S, Kouhkan A, Alizadeh AR, Shahverdi AH, NasrEsfahani MH, Sadighi Gilani MA, et al. Association of vitamin $\mathrm{D}$ status with semen quality and reproductive hormones in Iranian subfertile men. Andrology. 2017. 5:113-118.

Acharya S, Gowda CR. Lifestyle factors associated with infertility in a rural area: a cross-sectional study. Int J Med Sci Public Health. 2017. 6:502-506.

Adoamnei E, Mendiola J, Moñino-García M, López-Espín JJ, Navarrete-Muñoz EM, Torres-Cantero AM. Dietary intake of trace elements and semen quality and reproductive hormone levels in young men: relationship with fertility. Rev Int Androl. 2019. 17:46-54.

Agarwal A, Sengupta P, Durairajanayagam D. Role of L-carnitine in female infertility. Reprod Biol Endocrinol. 2018. 16:5. https:// doi.org/10.1186/s12958-018-0323-4

Ahmadi S, Bashiri R, Ghadiri-Anari A, Nadjarzadeh A. Antioxidant supplements and semen parameters: an evidence based review. Int J Reprod Biomed. 2016. 14:729-736.

Alahmar AT. Role of oxidative stress in male infertility: an updated review. J Hum Reprod Sci. 2019. 12:4-18.

Amaral A, Castillo J, Ramalho-Santos J, Oliva R. The combined human sperm proteome: cellular pathways and implications for basic and clinical science. Hum Reprod Update. 2014. 20: 40-62.

American Society for Reproductive Medicine. 2014 [cited 2019 May 6]. Available from: https://www.reproductivefacts.org/ news-and-publications/patient-fact-sheets-and-booklets/doc uments/fact-sheets-and-info-booklets/defining-infertility/

Amir AA, Kelly JM, Kleemann DO, Durmic Z, Blache D, Martin GB. Phyto-oestrogens affect fertilisation and embryo development in vitro in sheep. Reprod Fertil Dev. 2018. 30:1109-1115.

Arslan S, Akdevelioğlu Y. The relationship between female reproductive functions and vitamin D. J Am Coll Nutr. 2018. 37:546551.

Arvizu Boy M, Cortes A, Lajous-Loaza M, Chavarro JE. Sugarsweetened beverage consumption and infertility among participants of the mexican teachers' cohort. Proceedings of the American Society for Reproductive Medicine 2018 Scientific Congress \& Expo. 2018 Oct 6-10, Denver, CO, USA. p E125, Poster no. P-39.

Banihani SA. Effect of coenzyme Q10 supplementation on testosterone. Biomolecules. 2018. 8:172. https://doi.org/10.3390/ biom8040172 
Banihani SA. Vitamin $B_{12}$ and semen quality. Biomolecules. 2017. 7:42. https://doi.org/10.3390/biom7020042

Bawa R, Tyagi S. Correlation of microelements like plasma copper and zinc concentrations with female infertility. Int J Reprod Contracept Obstet Gynecol. 2017. 6:2351-2353.

Blomhoff R. Dietary antioxidants and cardiovascular disease. Curr Opin Lipidol. 2005. 16:47-54.

Bosdou JK, Konstantinidou E, Anagnostis P, Kolibianakis EM, Goulis DG. Vitamin D and obesity: two interacting players in the field of infertility. Nutrients. 2019. 11:1455. https://doi. org/10.3390/nu11071455

Braga DP, Halpern G, Setti AS, Figueira RC, Iaconelli A Jr, Borges EJr. The impact of food intake and social habits on embryo quality and the likelihood of blastocyst formation. Reprod Biomed Online. 2015. 31:30-38.

Chavarro JE, Rich-Edwards JW, Rosner BA, Willett WC. A prospective study of dietary carbohydrate quantity and quality in relation to risk of ovulatory infertility. Eur J Clin Nutr. 2009. 63:78-86.

Chavarro JE, Rich-Edwards JW, Rosner BA, Willett WC. Diet and lifestyle in the prevention of ovulatory disorder infertility. Obstet Gynecol. 2007. 110:1050-1058.

Chiu YH, Chavarro JE, Souter I. Diet and female fertility: doctor, what should I eat?. Fertil Steril. 2018. 110:560-569.

Colagar AH, Marzony ET, Chaichi MJ. Zinc levels in seminal plasma are associated with sperm quality in fertile and infertile men. Nutr Res. 2009. 29:82-88.

Condorelli RA, Calogero AE, Vicari E, La Vignera S. Chronic consumption of alcohol and sperm parameters: our experience and the main evidences. Andrologia. 2015. 47:368-379.

Cueto HT, Riis AH, Hatch EE, Wise LA, Rothman KJ, Sørensen HT, et al. Folic acid supplementation and fecundability: a Danish prospective cohort study. Eur J Clin Nutr. 2016. 70:66-71.

Cutillas-Tolín A, Mínguez-Alarcón L, Mendiola J, López-Espín JJ, Jørgensen N, Navarrete-Muñoz EM, et al. Mediterranean and Western dietary patterns are related to markers of testicular function among healthy men. Hum Reprod. 2015. 30:29452955.

da Silva TM, Maia MCS, Arruda JT, Approbato FC, Mendonça CR, Approbato MS. Folic acid does not improve semen parametrs in subfertile men: a double-blin, randomized, placebo-controlled study. JBRA Assisted Reprod. 2013. 17:152-157.

Danielewicz A, Przybyłowicz KE, Przybyłowicz M. Dietary patterns and poor semen quality risk in men: a cross-sectional study. Nutrients. 2018. 10:1162. https://doi.org/10.3390/ nu10091162

de Angelis C, Galdiero M, Pivonello C, Garifalos F, Menafra D, Cariati F, et al. The role of vitamin D in male fertility: a focus on the testis. Rev Endocr Metab Disord. 2017. 18:285-305.

EFSA NDA Panel (EFSA Panel on Dietetic Products, Nutrition and Allergies). Scientific opinion on the safety of caffeine. EFSA J. 2015. 13:4102. https://doi.org/10.2903/j.efsa.2015.4102

Eslamian G, Amirjannati N, Rashidkhani B, Sadeghi MR, Hekmatdoost A. Nutrient patterns and asthenozoospermia: a case-control study. Andrologia. 2017. 49:e12624. https://doi. org/10.1111/and.12624

Fontana R, Della Torre S. The deep correlation between energy metabolism and reproduction: a view on the effects of nutrition for women fertility. Nutrients. 2016. 8:87. https://doi.org/10. 3390/nu8020087

Garruti G, Depalo R, De Angelis M. Weighing the impact of diet and lifestyle on female reproductive function. Curr Med Chem. 2019. 26:3584-3592.

Gaskins AJ, Chiu YH, Williams PL, Keller MG, Toth TL, Hauser $\mathrm{R}$, et al. Maternal whole grain intake and outcomes of in vitro fertilization. Fertil Steril. 2016. 105:1503-1510.e4.

Gaskins AJ, Colaci DS, Mendiola J, Swan SH, Chavarro JE. Dietary patterns and semen quality in young men. Hum Reprod. 2012. 27:2899-2907.

Gaskins AJ, Nassan FL, Chiu YH, Arvizu M, Williams PL, Keller MG, et al. Dietary patterns and outcomes of assisted reproduction. Am J Obstet Gynecol. 2019. 220:567.e1-567.e18.

Gaskins AJ, Sundaram R, Buck Louis GM, Chavarro JE. Seafood intake, sexual activity, and time to pregnancy. J Clin Endocrinol Metab. 2018. 103:2680-2688.

Genazzani AD, Lanzoni C, Ricchieri F, Santagni S, Rattighieri E, Chierchia E, et al. Acetyl-L-carnitine (ALC) administration positively affects reproductive axis in hypogonadotropic women with functional hypothalamic amenorrhea. J Endocrinol Invest. 2011. 34:287-291.

Ghosh I, Sharma PK, Rahman M, Lahkar K. Sugar-sweetened beverage intake in relation to semen quality in infertile couples - a prospective observational study. Fertil Sci Res. 2019. 6:40-48.

Grieger JA, Grzeskowiak LE, Wilson RL, Bianco-Miotto T, Leemaqz SY, Jankovic-Karasoulos T, et al. Maternal selenium, copper and zinc concentrations in early pregnancy, and the association with fertility. Nutrients. 2019. 11:1609. https://doi. org/10.3390/nu11071609

Hahn KA, Wesselink AK, Wise LA, Mikkelsen EM, Cueto HT, Tucker KL, et al. Iron consumption is not consistently associated with fecundability among North American and Danish pregnancy planners. J Nutr. 2019. 149:1585-1595.

Hatch EE, Wesselink AK, Hahn KA, Michiel JJ, Mikkelsen EM, Sorensen HT, et al. Intake of sugar-sweetened beverages and fecundability in a North American preconception cohort. Epidemiology. 2018. 29:369-378.

Henkel R, Sandhu IS, Agarwal A. The excessive use of antioxidant therapy: a possible cause of male infertility?. Andrologia. 2019. 51:e13162. https://doi.org/10.1111/and.13162

Holick MF, Binkley NC, Bischoff-Ferrari HA, Gordon CM, Hanley DA, Heaney RP, et al. Evaluation, treatment, and prevention of vitamin D deficiency: an Endocrine Society clinical practice guideline. J Clin Endocrinol Metab. 2011. 96:1911-1930.

Irani M, Amirian M, Sadeghi R, Lez JL, Latifnejad Roudsari R. The effect of folate and folate plus zinc supplementation on endocrine parameters and sperm characteristics in sub-fertile men: a systematic review and meta-analysis. Urol J. 2017. 14:40694078.

Jacobsen BK, Jaceldo-Siegl K, Knutsen SF, Fan J, Oda K, Fraser GE. Soy isoflavone intake and the likelihood of ever becoming a mother: the Adventist Health Study-2. Int J Womens Health. 2014. 6:377-384.

Jamilian H, Jamilian M, Samimi M, Afshar Ebrahimi F, Rahimi M, Bahmani F, et al. Oral carnitine supplementation influences mental health parameters and biomarkers of oxidative stress in women with polycystic ovary syndrome: a randomized, double-blind, placebo-controlled trial. Gynecol Endocrinol. 2017. 33:442-447.

Jukic AM, Steiner AZ, Baird DD. Association between serum 25hydroxyvitamin $\mathrm{D}$ and ovarian reserve in premenopausal women. Menopause. 2015. 22:312-316.

Jurewicz J, Radwan M, Sobala W, Radwan P, Bochenek M, Hanke W. Dietary patterns and their relationship with semen quality. Am J Mens Health. 2018. 12:575-583.

Karayiannis D, Kontogianni MD, Mendorou C, Douka L, Mastrominas M, Yiannakouris N. Association between adherence to the Mediterranean diet and semen quality parameters in male partners of couples attempting fertility. Hum Reprod. 2017. 32:215-222.

Karayiannis D, Kontogianni MD, Mendorou C, Mastrominas M, Yiannakouris N. Adherence to the Mediterranean diet and IVF success rate among non-obese women attempting fertility. Hum Reprod. 2018. 33:494-502.

Karmon AE, Toth TL, Chiu YH, Gaskins AJ, Tanrikut C, Wright 
DL, et al. Male caffeine and alcohol intake in relation to semen parameters and in vitro fertilization outcomes among fertility patients. Andrology. 2017. 5:354-361.

Kim K, Wactawski-Wende J, Michels KA, Plowden TC, Chaljub EN, Sjaarda LA, et al. Dairy food intake is associated with reproductive hormones and sporadic anovulation among healthy premenopausal women. J Nutr. 2017. 147:218-226.

Kimáková T, Kuzmová L, Nevolná Z, Bencko V. Fish and fish products as risk factors of mercury exposure. Ann Agric Environ Med. 2018. 25:488-493.

Lee SR. Critical role of zinc as either an antioxidant or a prooxidant in cellular systems. Oxid Med Cell Longev. 2018. 2018: 9156285. https://doi.org/10.1155/2018/9156285

Li MC, Chiu YH, Gaskins AJ, Mínguez-Alarcón L, Nassan FL, Williams PL, et al. Men's intake of vitamin C and $\beta$-carotene is positively related to fertilization rate but not to live birth rate in couples undergoing infertility treatment. J Nutr. 2019. 149: 1977-1984.

Liese AD, Roach AK, Sparks KC, Marquart L, D’Agostino RB Jr, Mayer-Davis EJ. Whole-grain intake and insulin sensitivity: the Insulin Resistance Atherosclerosis Study. Am J Clin Nutr. 2003. 78:965-971.

life'sDHA. DHA Facts. 2020 [cited 2020 Apr 16]. Available from: https://www.lifesdha.com/en_AU/facts.html

Liu CY, Chou YC, Chao JC, Hsu CY, Cha TL, Tsao CW. The association between dietary patterns and semen quality in a general Asian population of 7282 males. PLoS One. 2015. 10:e0134224. https://doi.org/10.1371/journal.pone.0134224

Lyngsø J, Ramlau-Hansen CH, Bay B, Ingerslev HJ, Hulman A, Kesmodel US. Association between coffee or caffeine consumption and fecundity and fertility: a systematic review and doseresponse meta-analysis. Clin Epidemiol. 2017. 9:699-719.

Machtinger R, Gaskins AJ, Mansur A, Adir M, Racowsky C, Baccarelli AA, et al. Association between preconception maternal beverage intake and in vitro fertilization outcomes. Fertil Steril. 2017. 108:1026-1033.

Maeda E, Murata K, Kumazawa Y, Sato W, Shirasawa H, Iwasawa $\mathrm{T}$, et al. Associations of environmental exposures to methylmercury and selenium with female infertility: a case-control study. Environ Res. 2019. 168:357-363.

Majzoub A, Agarwal A. Systematic review of antioxidant types and doses in male infertility: benefits on semen parameters, advanced sperm function, assisted reproduction and live-birth rate. Arab J Urol. 2018. 16:113-124.

Martínez-Soto JC, Domingo JC, Cordobilla B, Nicolás M, Fernández L, Albero P, et al. Dietary supplementation with docosahexaenoic acid (DHA) improves seminal antioxidant status and decreases sperm DNA fragmentation. Syst Biol Reprod Med. 2016. 62:387-395.

Mascarenhas MN, Flaxman SR, Boerma T, Vanderpoel S, Stevens GA. National, regional, and global trends in infertility prevalence since 1990: a systematic analysis of 277 health surveys. PLoS Med. 2012. 9:e1001356. https://doi.org/10.1371/ journal.pmed.1001356

Mikkelsen EM, Riis AH, Wise LA, Hatch EE, Rothman KJ, Cueto HT, et al. Alcohol consumption and fecundability: prospective Danish cohort study. BMJ. 2016. 354:i4262. https://doi.org/ 10.1136/bmj.i4262

Mínguez-Alarcón L, Afeiche MC, Chiu YH, Vanegas JC, Williams PL, Tanrikut C, et al. Male soy food intake was not associated with in vitro fertilization outcomes among couples attending a fertility center. Andrology. 2015. 3:702-708.

MInguez-Alarcón L, Chavarro JE, Mendiola J, Roca M, Tanrikut $\mathrm{C}$, Vioque J, et al. Fatty acid intake in relation to reproductive hormones and testicular volume among young healthy men. Asian J Androl. 2017. 19:184-190.

Mumford SL, Garbose RA, Kim K, Kissell K, Kuhr DL, Omosigho
UR, et al. Association of preconception serum 25-hydroxyvitamin D concentrations with livebirth and pregnancy loss: a prospective cohort study. Lancet Diabetes Endocrinol. 2018. 6:725-732.

Muscogiuri G, Altieri B, de Angelis C, Palomba S, Pivonello R, Colao A, et al. Shedding new light on female fertility: the role of vitamin D. Rev Endocr Metab Disord. 2017. 18:273-283.

Nassan FL, Chavarro JE, Tanrikut C. Diet and men's fertility: does diet affect sperm quality?. Fertil Steril. 2018. 110:570-577.

Office of Dietary Supplements. Copper. 2020a [cited 2020 Jun 3]. Available from: https://ods.od.nih.gov/factsheets/CopperHealthProfessional/

Office of Dietary Supplements. Folate. 2020b [cited 2020 Jun 3]. Available from: https://ods.od.nih.gov/factsheets/FolateHealthProfessional/

Office of Dietary Supplements. Selenium. 2020c [cited 2020 Mar 11]. Available from: https://ods.od.nih.gov/factsheets/selenium-healthprofessional/

Office of Dietary Supplements. Vitamin B12. 2020d [cited 2020 Mar 30]. Available from: https://ods.od.nih.gov/factsheets/ VitaminB12-Consumer/

Office of Dietary Supplements. Vitamin D. 2020e [cited 2020 Oct 9]. Available from: https://ods.od.nih.gov/factsheets/VitaminD-HealthProfessional/

Office of Dietary Supplements. Zinc. 2020f [cited 2020 Jul 15]. Available from: https://ods.od.nih.gov/factsheets/ZincHealthProfessional

Oostingh EC, Steegers-Theunissen RP, de Vries JH, Laven JS, Koster MP. Strong adherence to a healthy dietary pattern is associated with better semen quality, especially in men with poor semen quality. Fertil Steril. 2017. 107:916-923.e2.

Poole R, Kennedy OJ, Roderick P, Fallowfield JA, Hayes PC, Parkes $\mathrm{J}$, et al. Coffee consumption and health: umbrella review of meta-analyses of multiple health outcomes. BMJ. 2017. 359: j5024. https://doi.org/10.1136/bmj.j5024

Ricci E, Noli S, Ferrari S, La Vecchia I, Cipriani S, De Cosmi V, et al. Alcohol intake and semen variables: cross-sectional analysis of a prospective cohort study of men referring to an Italian Fertility Clinic. Andrology. 2018. 6:690-696.

Ricci E, Viganò P, Cipriani S, Somigliana E, Chiaffarino F, Bulfoni A, et al. Coffee and caffeine intake and male infertility: a systematic review. Nutr J. 2017. 16:37. https://doi.org/10.1186/ s12937-017-0257-2

Rossi BV, Bressler LH, Correia KF, Lipskind S, Hornstein MD, Missmer SA. Lifestyle and in vitro fertilization: what do patients believe?. Fertil Res and Pract. 2016. 2:11. https://doi.org/10. 1186/s40738-016-0026-5

Salas-Huetos A, Moraleda R, Giardina S, Anton E, Blanco J, SalasSalvadó J, et al. Effect of nut consumption on semen quality and functionality in healthy men consuming a Western-style diet: a randomized controlled trial. Am J Clin Nutr. 2018. 108: 953-962.

Samimi M, Jamilian M, Ebrahimi FA, Rahimi M, Tajbakhsh B, Asemi Z. Oral carnitine supplementation reduces body weight and insulin resistance in women with polycystic ovary syndrome: a randomized, double-blind, placebo-controlled trial. Clin Endocrinol. 2016. 84:851-857.

Schisterman EF, Sjaarda LA, Clemons T, Carrell DT, Perkins NJ, Johnstone E, et al. Effect of folic acid and zinc supplementation in men on semen quality and live birth among couples undergoing infertility treatment: a randomized clinical trial. JAMA. 2020. 323:35-48.

Schliep KC, Zarek SM, Schisterman EF, Wactawski-Wende J, Trevisan M, Sjaarda LA, et al. Alcohol intake, reproductive hormones, and menstrual cycle function: a prospective cohort study. Am J Clin Nutr. 2015. 102:933-942.

Shaaker M, Rahimipour A, Nouri M, Khanaki K, Darabi M, Farzadi 
L, et al. Fatty acid composition of human follicular fluid phospholipids and fertilization rate in assisted reproductive techniques. Iran Biomed J. 2012. 16:162-168.

Sharma R, Biedenharn KR, Fedor JM, Agarwal A. Lifestyle factors and reproductive health: taking control of your fertility. Reprod Biol Endocrinol. 2013. 11:66. https://doi.org/10.1186/14777827-11-66

Shi K, Lu D, Dai Z. Correlation study of the microelement content in male infertility patients' blood and semen. Chin J Hum Sex. 2014. 23(5):28-30.

Showell MG, Mackenzie-Proctor R, Jordan V, Hart RJ. Antioxidants for female subfertility. Cochrane Database Syst Rev. 2020. 7:CD007807. https://doi.org/10.1002/14651858.CD007807. pub4

Somigliana E, Paffoni A, Lattuada D, Colciaghi B, Filippi F, La Vecchia I, et al. Serum levels of 25-hydroxyvitamin D and time to natural pregnancy. Gynecol Obstet Invest. 2016. 81:468471.

Souter I, Chiu YH, Batsis M, Afeiche MC, Williams PL, Hauser R, et al. The association of protein intake (amount and type) with ovarian antral follicle counts among infertile women: results from the EARTH prospective study cohort. BJOG. 2017. 124: 1547-1555.

Soylu LÍ, Jensen A, Juul KE, Kesmodel US, Frederiksen K, Kjaer $\mathrm{SK}$, et al. Coffee, tea and caffeine consumption and risk of primary infertility in women: a Danish cohort study. Acta Obstet Gynecol Scand. 2018. 97:570-576.

Toledo E, Lopez-del Burgo C, Ruiz-Zambrana A, Donazar M, Navarro-Blasco I, Martínez-González MA, et al. Dietary patterns and difficulty conceiving: a nested case-control study. Fertil Steril. 2011. 96:1149-1153.

US Food and Drug Administration. Advice about eating fish: for women who are or might become pregnant, breastfeeding mothers, and young children. 2017 [cited 2020 Aug 8]. Available from: https://www.fda.gov/Food/FoodborneIllnessContaminants/Metals/ucm393070.htm

Vanegas JC, Afeiche MC, Gaskins AJ, Mínguez-Alarcón L, Williams PL, Wright DL, et al. Soy food intake and treatment outcomes of women undergoing assisted reproductive technology. Fertil Steril. 2015. 103:749-755.e2.

Wesselink AK, Wise LA, Rothman KJ, Hahn KA, Mikkelsen EM, Mahalingaiah S, et al. Caffeine and caffeinated beverage consumption and fecundability in a preconception cohort. Reprod Toxicol. 2016. 62:39-45.

WHO. Global prevalence of infertility, infecundity and childlessness. 2019 [cited 2020 Sep 11]. Available from: https://www. who.int/reproductivehealth/topics/infertility/burden/en/

WHO. Healthy diet. 2020 [cited 2020 Apr 29]. Available from: https://www.who.int/news-room/fact-sheets/detail/healthy -diet

WHO. WHO recommendations on antenatal care for a positive pregnancy experience. World Health Organization, Geneva, Switzerland. 2016. p 1-196.

Wise LA, Wesselink AK, Tucker KL, Saklani S, Mikkelsen EM, Cueto $\mathrm{H}$, et al. Dietary fat intake and fecundability in 2 preconception cohort studies. Am J Epidemiol. 2018. 187:60-74.

Wocławek-Potocka I, Mannelli C, Boruszewska D, KowalczykZieba I, Waśniewski T, Skarżyński DJ. Diverse effects of phytoestrogens on the reproductive performance: cow as a model. Int J Endocrinol. 2013. 2013:650984. https://doi.org/10.1155/ 2013/650984

Zhao J, Dong X, Hu X, Long Z, Wang L, Liu Q, et al. Zinc levels in seminal plasma and their correlation with male infertility: a systematic review and meta-analysis. Sci Rep. 2016. 6:22386. https://doi.org/10.1038/srep22386

Zheng LP, Zhu X, Qin HY, Xu CL, Li SK. The comparative analysis of trace elements in blood and seminal plasma of infertile and healthy male. Prog Mod Biomed. 2012. 2012:681-683.

Zhu CL, Xu QF, Li SX, Wei YC, Zhu GC, Yang C, et al. Investigation of serum vitamin D levels in Chinese infertile men. Andrologia. 2016. 48:1261-1266.

Zhu F, Chen C, Zhang Y, Chen S, Huang X, Li J, et al. Elevated blood mercury level has a non-linear association with infertility in U.S. women: data from the NHANES 2013-2016. Reprod Toxicol. 2020. 91:53-58. 